\title{
Suppurative Granuloma
}

National Cancer Institute

\section{Source}

National Cancer Institute. Suppurative Granuloma. NCI Thesaurus. Code C3919.

A granuloma caused by infectious organisms and characterized by the presence of abscess formation. 